\section{Ultrasound-guided genitourinary interventions: principles and techniques}

\author{
Byung Kwan Park
}

Department of Radiology, Samsung Medical Center, Sungkyunkwan University School of Medicine, Seoul, Korea

Ultrasound (US) is often used to guide various interventional procedures in the genitourinary (GU) tract because it can provide real-time imaging without any radiation hazard. Moreover, US can clearly visualize the pathway of an aspiration or biopsy needle to ensure the safety of the intervention. US guidance also helps clinicians to access lesions via the transabdominal, transhepatic, transvaginal, transrectal, and transperineal routes. Hence, US-guided procedures are useful for radiologists who wish to perform GU interventions. However, US-guided procedures and interventions are difficult for beginners because they involve a steep initial learning curve. The purpose of this review is to describe the basic principles and techniques of US-guided GU interventions.

Keywords: Ultrasonography, interventional; Urogenital system; Radiology, interventional

\section{Introduction}

Ultrasound (US) is useful for guiding genitourinary (GU) interventions, because it can provide realtime imaging [1]. Moreover, US has the following additional advantages over computed tomography (CT): it is a small and portable modality, has low medical costs, and poses no radiation hazard. Therefore, US is frequently used to guide aspiration, biopsy, and ablation. However, because the technique is operator-dependent, it involves a steep initial learning curve. Hence, it is not easy for beginners to become familiar with US guidance.

Few reports have been published regarding how to perform US-guided procedures in the GU tract. The purpose of this review is to describe the basic principles and techniques of US-guided GU interventions.

\section{Basic Principles}

US-guided interventions should fulfil several basic requirements. Firstly, the shortest possible skinto-lesion distance under a good sonic window should be chosen when determining the skin entry site. Longer skin-to-lesion distances are more susceptible to inaccurate targeting. Moreover, a longer aspiration or biopsy needle pathway may lead to unnecessary tissue damage and increase the risk of bleeding. A very large amount of bleeding is often related to procedures that are not completed because of increasing pain, decreasing blood pressure, and a worsening sonic window. It must be

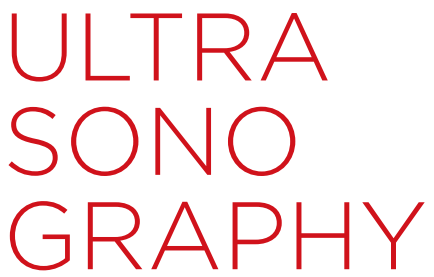

REVIEW ARTICLE

https://doi.org/10.14366/usg.17026 pISSN: 2288-5919 • elSSN: 2288-5943 Ultrasonography 2017;36:336-348

Received: March 11, 2017

Revised: May 28, 2017

Accepted: May 29, 2017

Correspondence to: Byung Kwan Park, MD, Department of Radiology, Samsung Medical Center, Sungkyunkwan University School of Medicine, 81 Irwon-ro, Gangnam-gu, Seoul 06351, Korea

Tel. +82-2-3410-6457

Fax. +82-2-3410-0084

E-mail: rapark@skku.edu

This is an Open Access article distributed under the terms of the Creative Commons Attribution NonCommercial License (http://creativecommons.org/ licenses/by-nc/3.0/) which permits unrestricted noncommercial use, distribution, and reproduction in any medium, provided the original work is properly cited.

Copyright (c) 2017 Korean Society of Ultrasound in Medicine (KSUM)

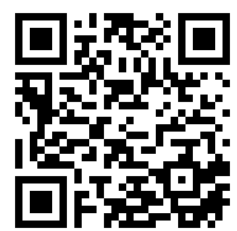

How to cite this article:

Park BK. Ultrasound-guided genitourinary interventions: principles and techniques. Ultrasonography 2017 0ct:36(4):336-348. 
kept in mind that a good sonic window should be secured while minimizing the skin-to-lesion distance. When a good sonic window is not available with the shortest skin-to-lesion distance, another pathway should be investigated.

Secondly, needle pathways should avoid critical organs, such as bowel loops, the great vessels, and the urinary tract (Fig. 1). Otherwise, radiologists may encounter many serious complications that require emergency intervention or surgery. For instance, bowel perforation can result in peritonitis, abscess, or sepsis, all of which are life-threatening complications. Active bleeding from large vessels is also a serious complication that requires an emergency intervention or surgery. Urine leakage may also require interventional procedures, such as ureter catheterization or percutaneous drainage.

Thirdly, the entire needle length or pathway should be observable on sonograms (Fig. 1) [2]. If the tip is out of view, the advancing needle must be stopped and withdrawn to prevent unwanted tissue damage. Frequently, the echo from the needle body is misinterpreted as emanating from the needle tip. In a clinical setting, such a mistake can lead to unwanted tissue damage, because the tip of the needle may be inserted into critical organs such as the bowel loops, the greater vessels, or the ureter.

Fourthly, radiologists must check whether patients have a bleeding tendency or coagulopathy. Specifically, their international normalized ratio (INR) should be less than 1.5-1.8, and their platelet count should be greater than $5 \times 10^{4} / \mu \mathrm{L}$ before an interventional procedure is begun. If the INR is greater than 1.5 , or the platelet count is less than $5 \times 10^{4} / \mu \mathrm{L}$, the deficient coagulation factors or platelets should be corrected before the intervention is carried out. Interventional procedures should not be begun before correcting a delayed prothrombin time or severe thrombocytopenia.

Lastly, to prevent infection, aseptic preparation for percutaneous procedures, such as transabdominal or transperineal procedures, is requisite. US-guided procedures via these routes do not require antibiotic medication if the interventional procedure is aseptically conducted. However, aseptic techniques cannot be used for the transvaginal and transrectal approaches. Therefore, when performing US-guided procedures via these routes, physicians should premedicate using antibiotics. A rectal enema is also necessary, because stools must be evacuated before the procedure; this minimizes the likelihood that bacteria will be introduced along the needle pathway.

\section{US-Guided Aspiration}

US guidance is frequently used to aspirate fluid from renal cysts $[3-5]$, pelvic lymphoceles $[6,7]$, adnexa cysts $[8,9]$, and pelvic abscesses $[10,11]$. Percutaneous drainage of this kind is an appropriate management strategy for such diseases, because the technique can completely drain the infected fluid via internal catheterization. However, a catheter is not technically easy to insert into small, infected cysts that are usually less than $2-3 \mathrm{~cm}$ in diameter (Fig. 2). Similarly, US can be used to guide the treatment of symptomatic, cystic masses that cause pain. US-guided aspiration alone is a conservative treatment that can relieve symptoms.

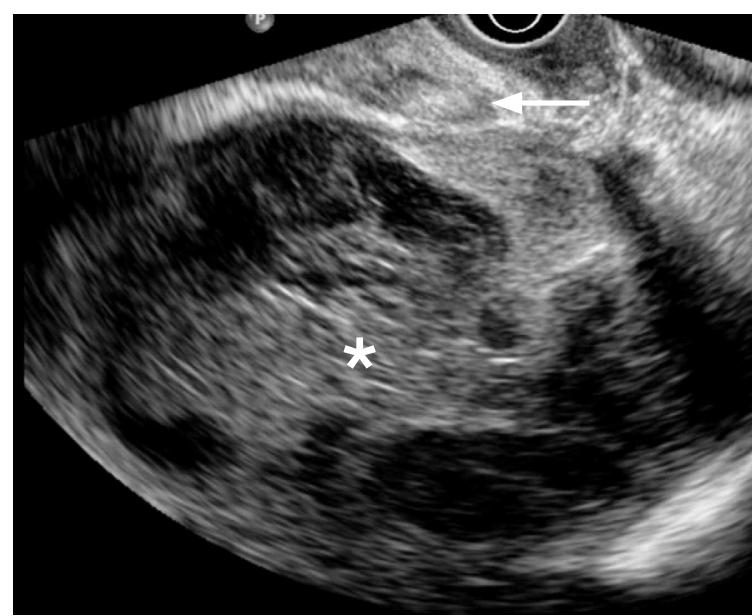

A

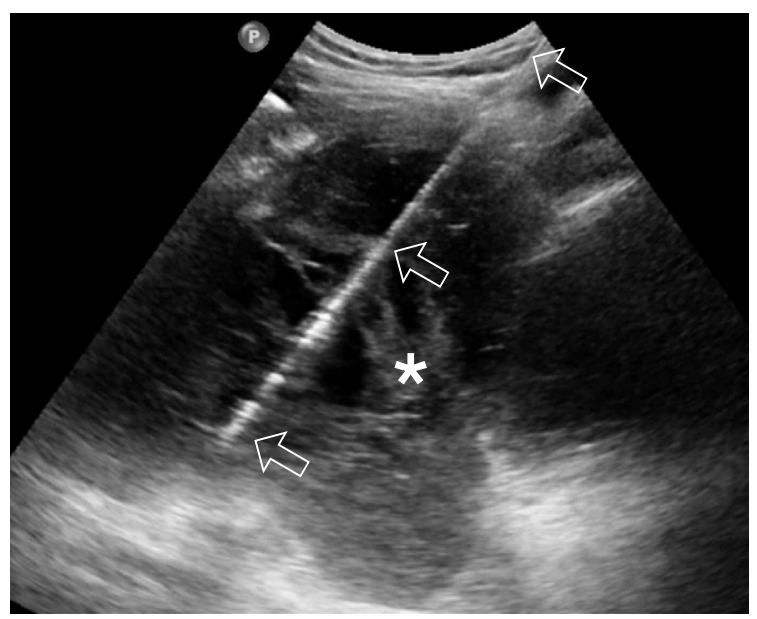

B

Fig. 1. A 54-year-old woman with lymphocele.

A. Transvaginal ultrasonography shows a 12-cm infected lymphocele (asterisk) divided into multiple chambers with septa. Aspiration was impossible via the transvaginal approach because a bowel loop (arrow) was interposed between the vagina and the lymphocele. B. Transabdominal ultrasonography shows an 18-gauge aspiration needle (open arrows), which is clearly visible from the needle tip to the skin entry. The amount of aspirated pus was only $60 \mathrm{~mL}$ because multiple septa (asterisk) were present. 
However, combining cyst aspiration with sclerotherapy is frequently recommended in this clinical setting, because the recurrence rate is high [3-5].

The thickness and length of the needle are important for successfully aspirating cystic fluid. In cases of an infected or haemorrhagic cyst, an 18-gauge or thicker needle should be used, because infected or haemorrhagic fluid is much thicker than simple cystic fluid. That is, abscess pus and cystic haematomas are difficult to aspirate using a 19-gauge or thinner needle, because these fluids have a high viscosity (Figs. 1-3). Deep cystic masses require a long needle; this increases intra-needle resistance. To aspirate fluid from deeper cystic masses, the negative pressure must be increased when a needle of the same gauge is used. Accordingly, the aspiration needle should be broader if the skin-to-lesion distance is longer,

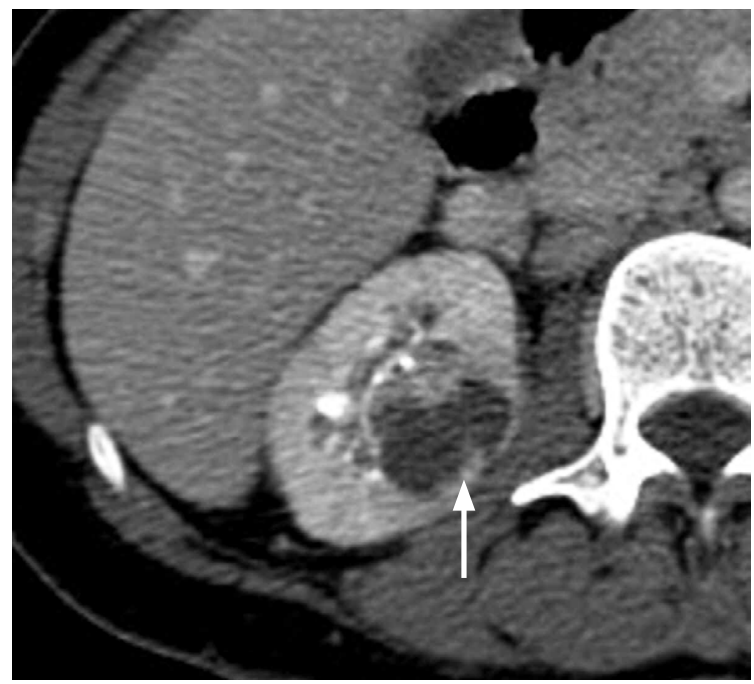

A

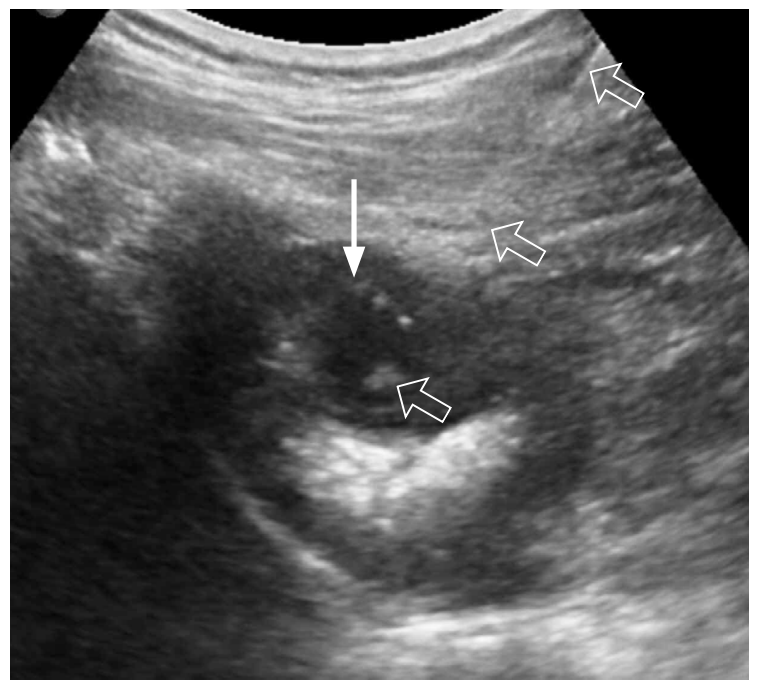

B

Fig. 2. A 43-year-old woman with a renal abscess.

A. A contrast-enhanced axial computed tomography image shows a right renal abscess (arrow) that measured $2.8 \mathrm{~cm}$. B. Transabdominal ultrasonography shows the entire pathway of an aspiration needle (arrow), which was appropriately placed within a right renal abscess (open arrows). A total of $5 \mathrm{~mL}$ of pus was aspirated using an 18-gauge needle with a length of $18 \mathrm{~cm}$.

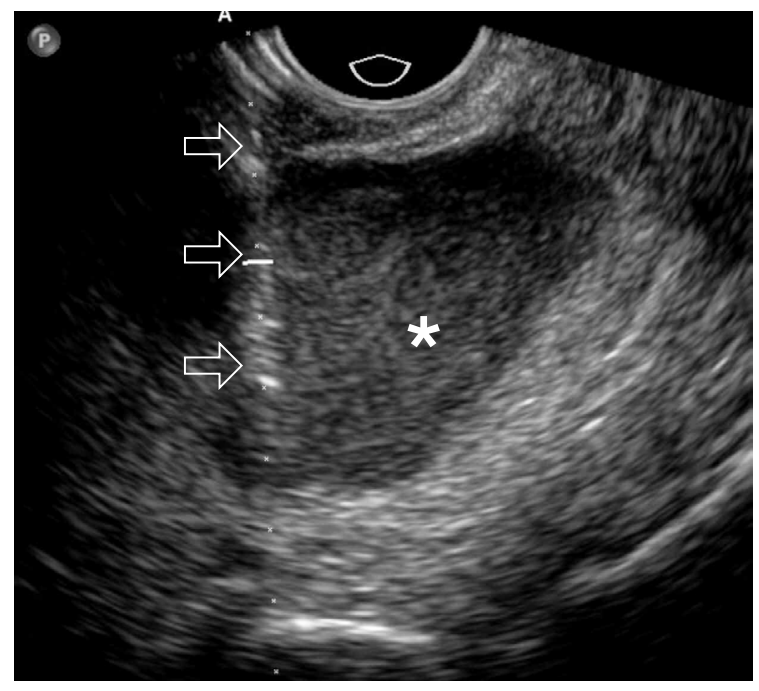

A

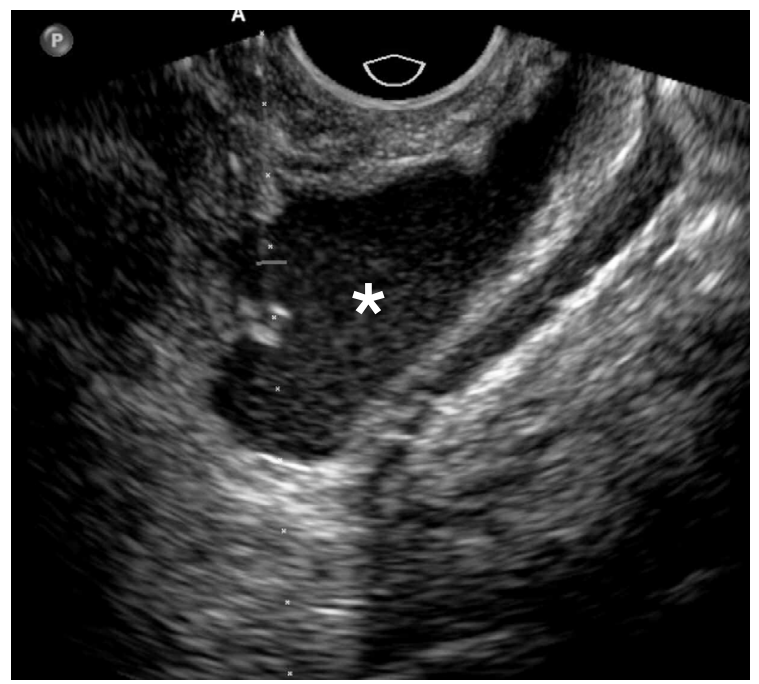

B

Fig. 3. A 62-year-old woman with ovarian cancer.

A. Transvaginal ultrasonography shows an 18-gauge needle (open arrows) placed into the malignant ascites (asterisk) in the pelvic cavity. B. Transvaginal ultrasonography shows that the ascites (asterisk) decreased during the aspiration procedure. A total of 2,300 mL of ascites was aspirated. 
even when simple cystic fluid is being aspirated.

Importantly, to ensure a successful procedure, the distance between the skin entry site and the target lesion should be measured before aspiration is begun. Deeper cystic masses require longer aspiration needles. Commercially available aspiration needles are usually less than $20 \mathrm{~cm}$ long. However, the transvaginal and transrectal approaches frequently require a needle that is $20 \mathrm{~cm}$ or more in length, because pelvic cystic masses are deep, and because the needle operator must hold a large part of the needle during these procedures.

Several more factors must be considered to ensure successful aspiration; namely, the number of septa and the maturity of the abscess. Furthermore, radiologists must be meticulous in their manipulation of the needle. If there are more septa, aspiration is less effective because the cystic mass is composed of many divided chambers (Fig. 1). Therefore, patients and clinicians must be informed when a septate cystic mass will be difficult to aspirate completely.

Immature abscesses also limit complete aspiration. They are not fully liquefied, so even appropriate targeting using a thick needle cannot aspirate them effectively. It may take several days, and antibiotic medication, for an early-stage abscess to become mature.

On a separate note, unskilled needle use can cause mechanical damage to cystic masses, and internal bleeding may develop as a result, distending the lesion and counteracting the aspiration. This is important, because bloody aspirations cause specimens to be inadequate for cytological examinations. More importantly, internal bleeding can make patients' symptoms worse. To prevent unnecessary haemorrhaging in the cystic mass, manipulation of the needle must be minimized.

Additionally, it should be noted that the principles and techniques of US-guided aspiration are the same as those of other USguided GU visceral interventional procedures, including antegrade pyelography, percutaneous nephrostomy, and percutaneous drainage.

\section{US-Guided Biopsy}

\section{Renal Mass Biopsy}

Incidental renal masses are increasingly detected on images from routine abdominal CT scans. Some small $(<4 \mathrm{~cm})$ renal masses require percutaneous biopsy, because smaller renal masses are more likely to be benign (Fig. 4) [12-14]. Renal mass biopsy is indicated when a patient has known extrarenal primary cancer, an unresectable renal cell carcinoma, a serious co-existing disease, a tumour-like infection, a hyper-attenuating or homogeneously enhancing mass, a Bosniak III or IV lesion, or multiple solid renal masses; renal mass biopsy should also be carried out prior to thermal ablation or if the patient is under active surveillance [12-14]. It is not easy to biopsy small renal masses under US guidance: the lesion size and location, nature of the lesion (e.g., solid or cystic), and number of biopsy cores are associated with successful biopsy. The non-diagnostic rate is higher when the renal mass is $2 \mathrm{~cm}$ or less in diameter, a cystic tumour, an upper tumour, or biopsied using

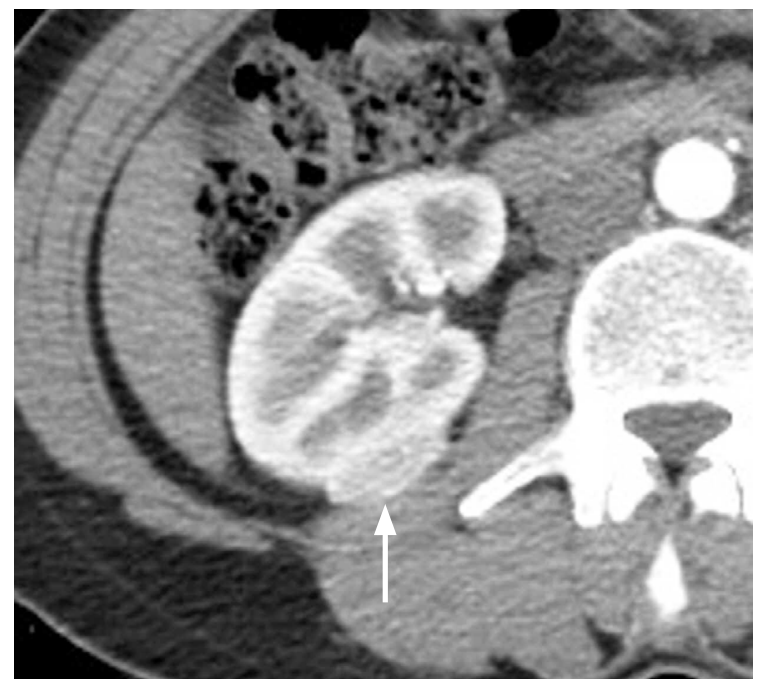

A

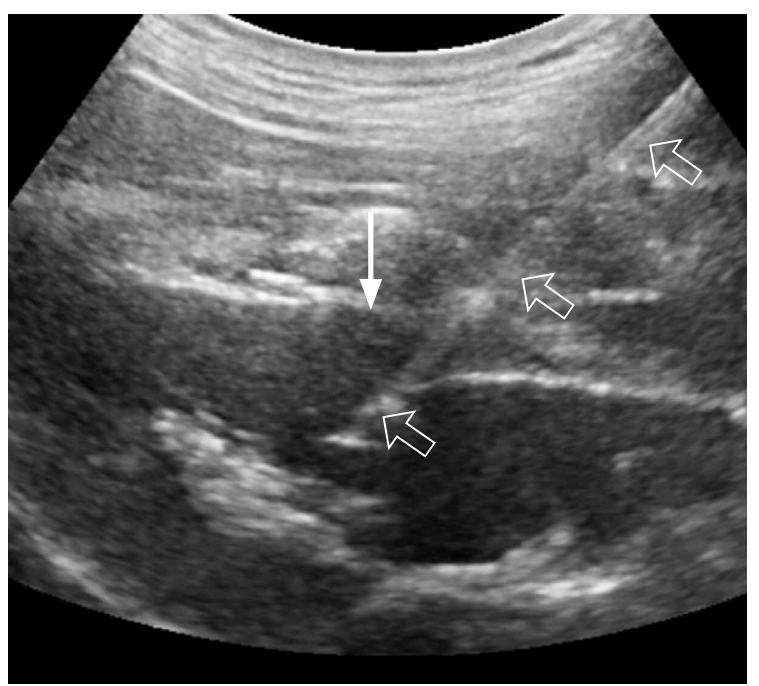

B

Fig. 4. A 45-year-old woman with an angiomyolipoma.

A. Contrast-enhanced axial computed tomography shows a $2.6-\mathrm{cm}$ solid renal mass (arrow) located at the posterior cortex of the inter-polar right kidney. B. Longitudinal ultrasonography shows the lesion (arrow), which was targeted with an 18-gauge biopsy needle (open arrows). The histologic diagnosis was angiomyolipoma. 
3 or fewer cores (Fig. 5) [15]. Accordingly, the diagnostic rate for USguided small $(<4 \mathrm{~cm})$ renal mass biopsies is $81 \%$ [15], while that for US-guided large $(\geq 4 \mathrm{~cm})$ renal mass biopsies ranges from $82 \%$ to $92 \%[16,17]$. Thus, US-guided biopsy can easily be used to sample large renal tumours; however, in larger renal masses, the likelihood of central necrosis is higher. Therefore, to prevent the sampling of non-diagnostic tissue, the peripheral area of large tumours should be biopsied (Fig. 6).

CT-guided renal mass biopsy yields a higher diagnostic rate than US-guided renal mass biopsy. The diagnostic rate of CT-guided renal mass biopsy has been reported to range from $94 \%$ to $98 \%$ [18-20], while that of US-guided renal mass biopsy has been found to range from $81 \%$ to $92 \%$ [15-17]. When a renal mass is visible on US, USguided biopsy is recommended. Conversely, when a renal mass is

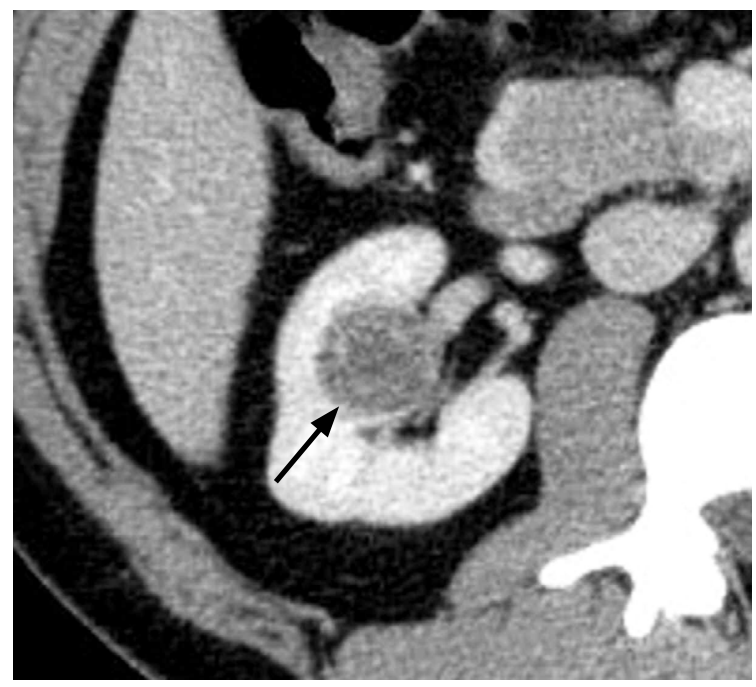

A

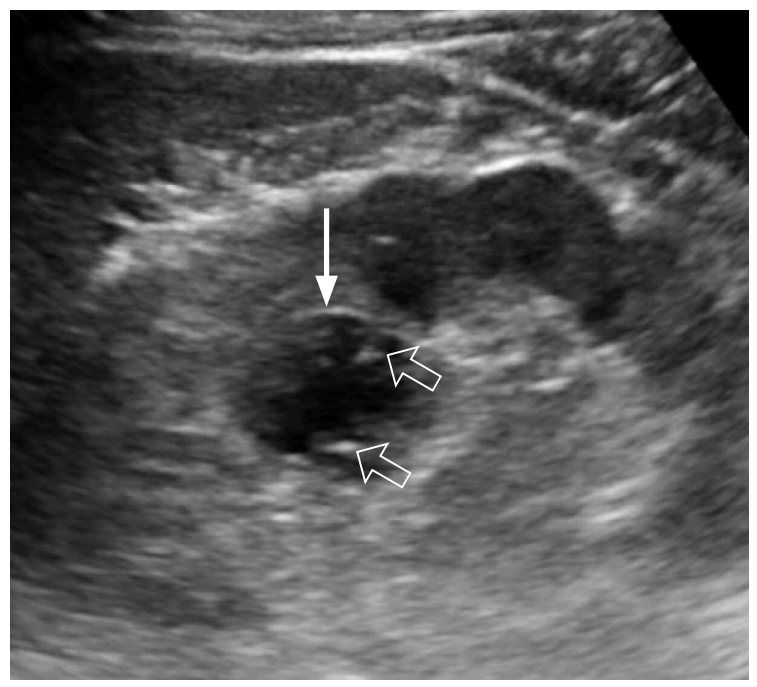

B

Fig. 5. A 38-year-old man with a Bosniak III cyst.

A. Contrast-enhanced axial computed tomography shows a 2.8-cm Bosniak III cyst (arrow) in the right kidney. B. Longitudinal ultrasonography shows the lesion (arrow), which was targeted with an 18-gauge biopsy needle (open arrows). The biopsy core consisted of non-diagnostic tissue because a small tissue sample was obtained from the lesion.

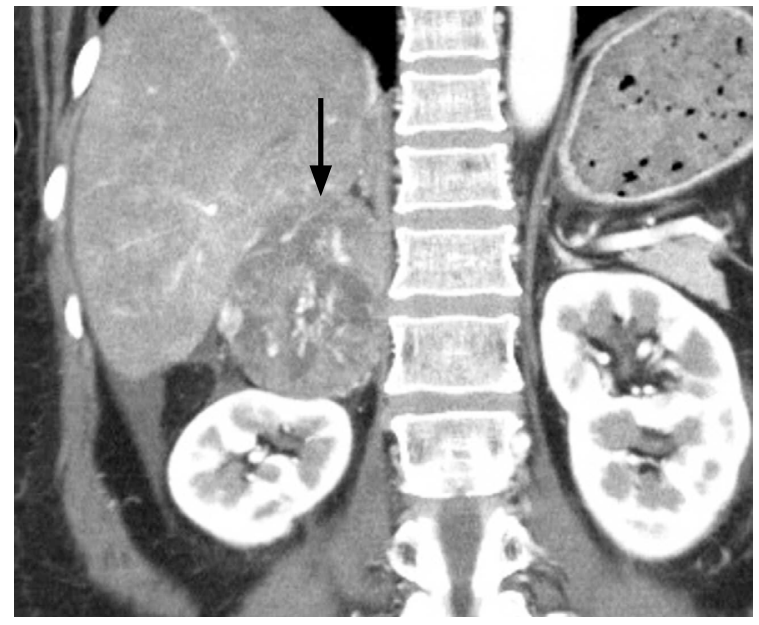

A

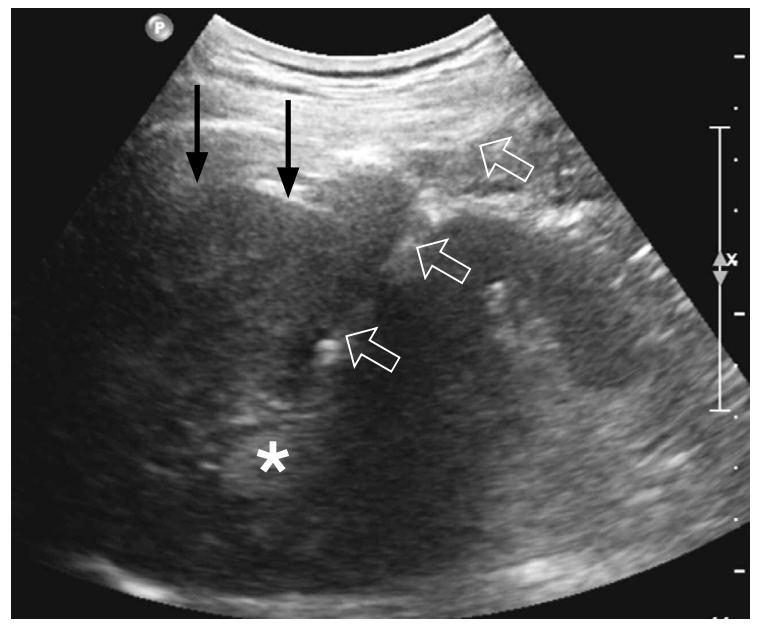

B

Fig. 6. A 58-year-old woman with adrenocortical carcinoma.

A. Contrast-enhanced coronal computed tomography shows a 7.6-cm solid tumour (arrow) originating from the right adrenal gland. She also had multiple pulmonary metastases (not shown), suggesting stage IV disease. B. Extrahepatic ultrasonography shows the lesion (arrows), which was targeted with an 18-gauge biopsy needle (open arrows). Two biopsy cores were sampled from the lesion periphery, but not the central area of necrosis (asterisk). The histologic diagnosis was adrenocortical carcinoma. 
not clearly visible on US, a CT-guided biopsy should be performed.

\section{Adrenal Mass Biopsy}

Incidental adrenal masses are mostly benign, and most are diagnosed as adenomas $[21,22]$. Adrenal mass biopsy is performed when the $\mathrm{CT}$ features of an adrenal mass are not consistent with adenoma, because $\mathrm{CT}$ is the best imaging modality for diagnosing adenoma [23-26]. However, biochemical tests should also be performed prior to adrenal mass biopsy, because subclinical pheochromocytoma must be excluded [26]. A high suspicion of adrenal diseases that usually require medical treatment, such as lymphoma, metastasis, unresectable or metastatic adrenocortical carcinoma, or cancer-mimicking adrenal tuberculosis, is also an indication for adrenal biopsy to avoid unnecessary surgery (Fig. 6). When adenoma or myelolipoma is strongly suggested on $\mathrm{CT}$ or magnetic resonance imaging (MRI), adrenal mass biopsy should be avoided $[27,28]$.

Many right adrenal or right upper pole renal masses are not clearly visible or safely accessible via an extrahepatic approach. To make such lesions clearly visible or safely accessible, a US-guided transhepatic approach can be used (Fig. 7) [29]. The normal liver parenchyma provides a good sonic window, so that right adrenal or upper renal masses are clearly visible on the US display. However, a transhepatic biopsy should only be carried out when the lesions are not visible via an extrahepatic approach, which usually provides a shorter skin-to-lesion distance than the transhepatic approach
(Fig. 6). Accordingly, the extrahepatic approach causes less tissue damage, because a shorter length of tissue is penetrated. However, transhepatic biopsies are not recommended in patients with chronic liver disease, a bleeding tendency, or coagulopathy.

The diagnostic rate of CT-guided adrenal mass biopsy is much higher than that of US-guided biopsy, because most adrenal masses cannot be seen using US [30]. Therefore, adrenal mass biopsies mostly depend on CT guidance [31-33]. However, when an adrenal mass is clearly visible and accessible using US, a US-guided biopsy should be performed to avoid exposing the patient to radiation (Figs. $6,7)$.

\section{Renal Parenchymal Biopsy}

To identify renal parenchymal diseases, it is necessary to perform percutaneous biopsy of the renal cortex $[34,35]$. In this regard, US is useful for evaluating renal size, echo, and perfusion, as well as in guiding the renal cortex biopsy (Fig. 8). It is difficult to sample the renal cortex, which is approximately $1 \mathrm{~cm}$ in thickness, and mistargeting is common in renal cortex biopsy. When the renal medulla or sinus is targeted, intractable bleeding or haematuria may occur as a result of mechanical injury to large vessels [36]. Such cases may require arterial embolization to treat an arteriovenous fistula.

\section{Pelvic Mass Biopsy}

Pelvic solid masses can be biopsied via the transvaginal [37,38],

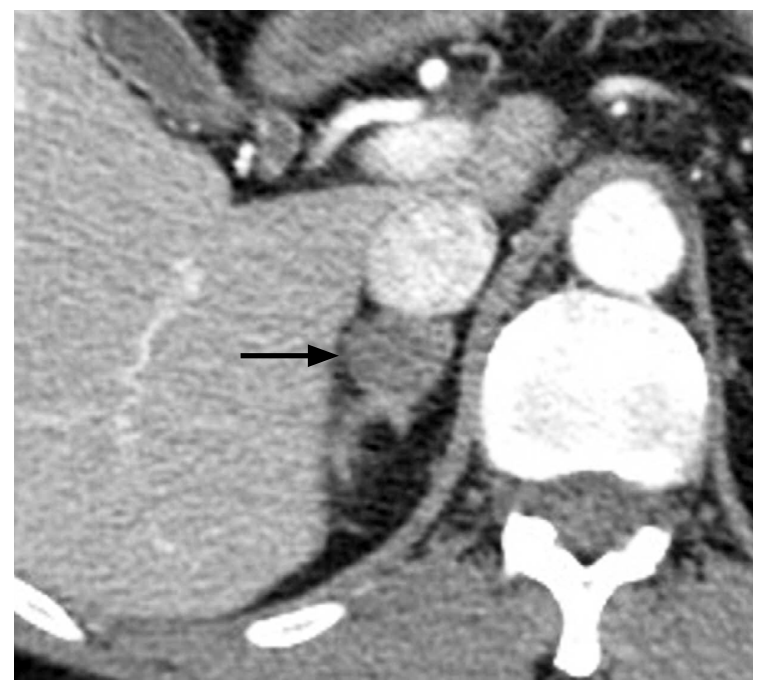

A

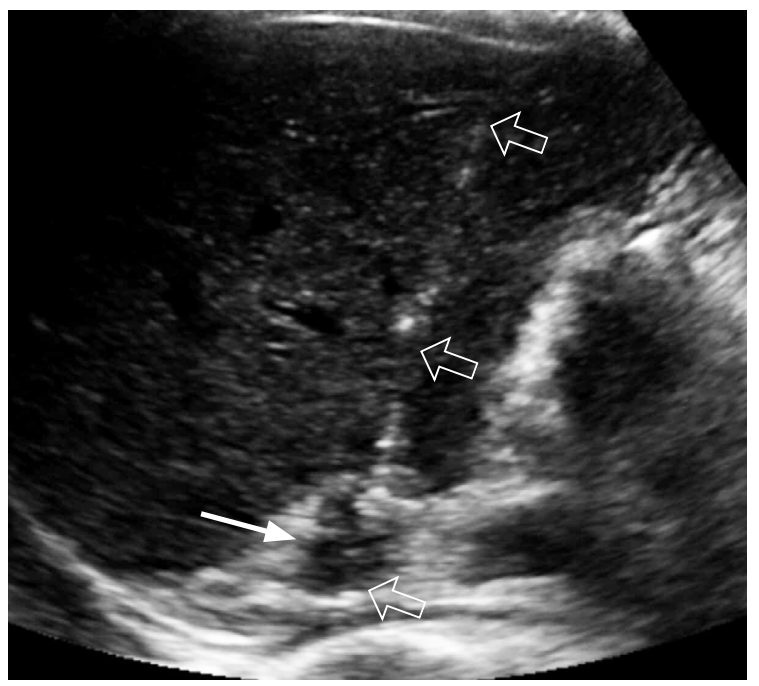

B

Fig. 7. A 59-year-old woman with schwannoma.

A. Contrast-enhanced axial computed tomography shows a $2.1-\mathrm{cm}$ solid tumour (arrow) in the right adrenal gland. The lesion has a low percentage wash of contrast material on adrenal computed tomography. She was diagnosed with lung cancer. B. Transhepatic ultrasonography shows the lesion (arrow), which was targeted with an 18-gauge biopsy needle (open arrows). This histologic diagnosis was schwannoma. 
transrectal $[39,40]$, or transperineal [41] routes (Fig. 9). These routes have some advantages over the transabdominal route. Generally, pelvic masses are not technically easy to target via the transabdominal route, because various bowel loops and vessels intervene in the path of the biopsy. In contrast, the transvaginal and transrectal approaches frequently provide a safe pathway for a biopsy needle, avoiding injury to these critical organs. Moreover, the transducer-to-lesion distance is shorter with the transvaginal, transrectal, and transperineal approaches than with the transabdominal approach. However, an aseptic biopsy is not possible when using the transvaginal or transrectal approach. Therefore, the number of tissue samples should be minimized in cases where a histological diagnosis is sufficient. Rectal evacuation and antibiotic medication are strongly recommended before transrectal biopsy to minimize the likelihood of infection.

\section{Prostate Biopsy}

Transrectal US (TRUS)-guided biopsies are still a mainstay for

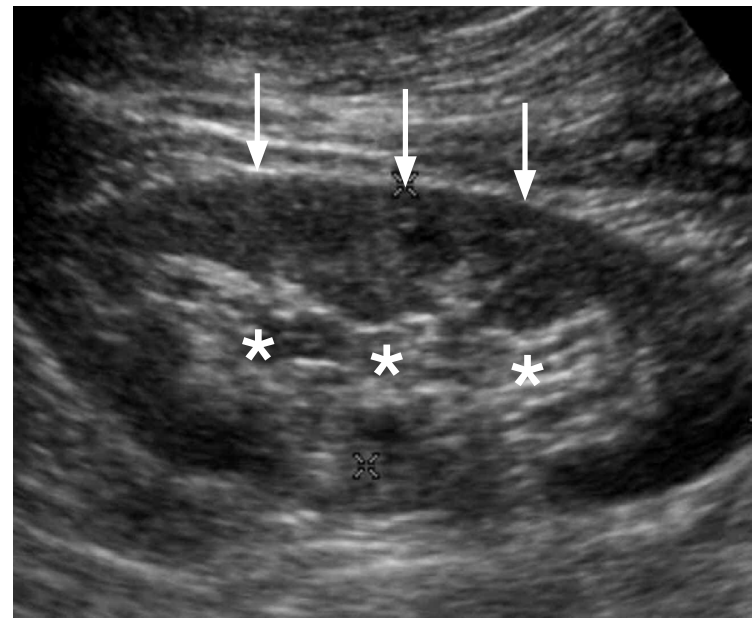

A

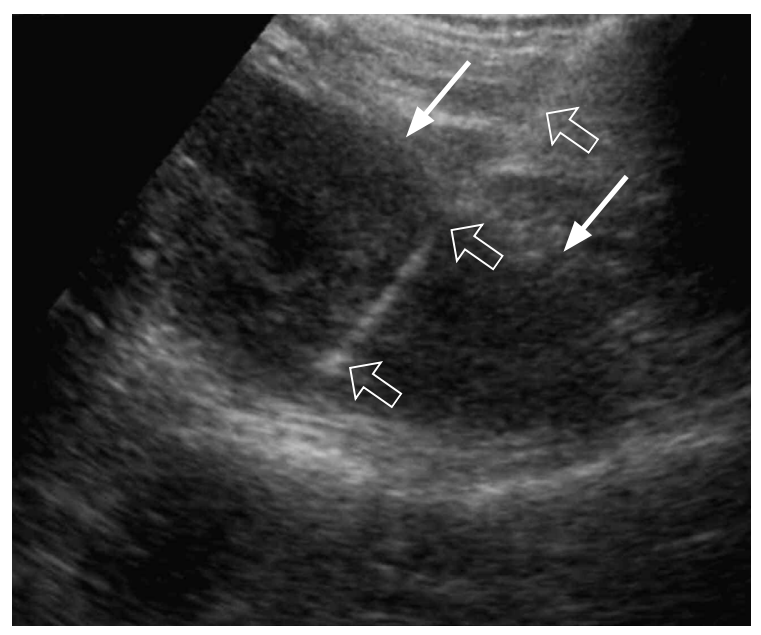

B

Fig. 8. A 37-year-old woman with glomerulonephritis.

A. Longitudinal ultrasonography shows a hypoechoic cortex (arrows) and a hyperechoic sinus (asterisks) in the left kidney. B. Longitudinal ultrasonography shows only a hyperechoic cortex (arrows), which was sampled with an 18-gauge biopsy needle (open arrows) in order to achieve an accurate and safe biopsy.

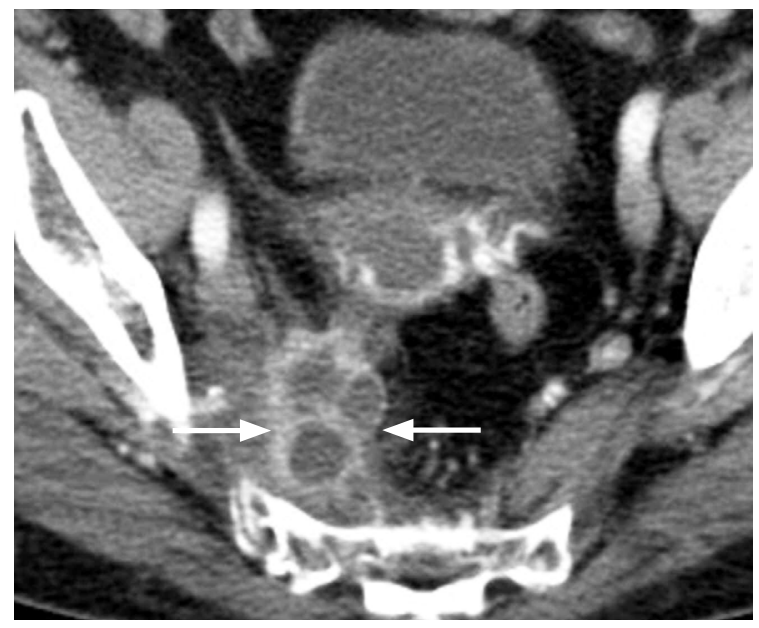

A

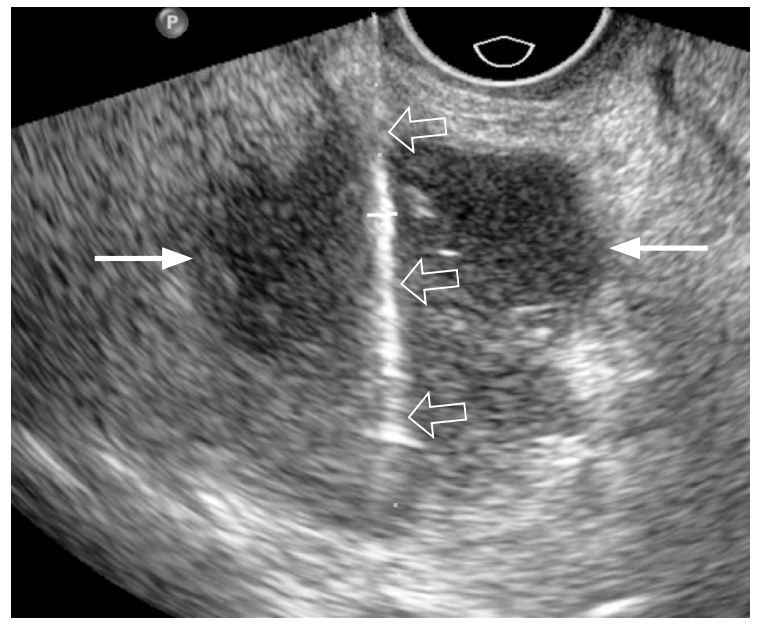

B

Fig. 9. An 80-year-old woman with squamous cell carcinoma.

A. Contrast-enhanced axial computed tomography shows a 3.7-cm cystic mass (arrows) in the right pyriform muscle. The lesion has thick septa and a wall, suggesting a malignant tumour. B. Transvaginal ultrasonography shows the cystic lesion (arrows), which was sampled with an 18-gauge biopsy needle (open arrows). The histologic diagnosis was squamous cell carcinoma. 
diagnosing prostate cancer $[42,43]$. However, a substantial number of significant cancers are not detected using TRUS-guided biopsy alone [44]. Recent studies have shown that the cancer detection rate is higher in MRI-TRUS fusion images [45-47]. Frequently, TRUS cannot clearly depict a lesion, even though it is clearly visible on magnetic resonance (MR) images. If the pre-biopsy MR images are fused with the TRUS images, prostate lesions that are unclear on TRUS can be localized in real time (Fig. 10). Thus, abnormal prostate lesions should be graded using the Prostate Imaging and Report and Data System (PI-RADS), and a fusion biopsy is recommended if the lesion is classified as PI-RADS 4 or 5 [48]. However, MRITRUS fusion may have technical limitations or considerations for the following reasons. Firstly, the prostate, which is usually seen as a triangle in transverse axial images, is frequently deformed into a banana shape when a TRUS probe is introduced (Fig. 10). Secondly, axial MR images are obtained perpendicular to the urethra. However, such axial images cannot be taken using TRUS, because oblique axial images taken using TRUS are not perpendicular to the urethra. Accordingly, axial TRUS images can never be truly axial; instead, they are merely oblique-axial or coronal (Fig. 11). Thirdly, PI-RADS

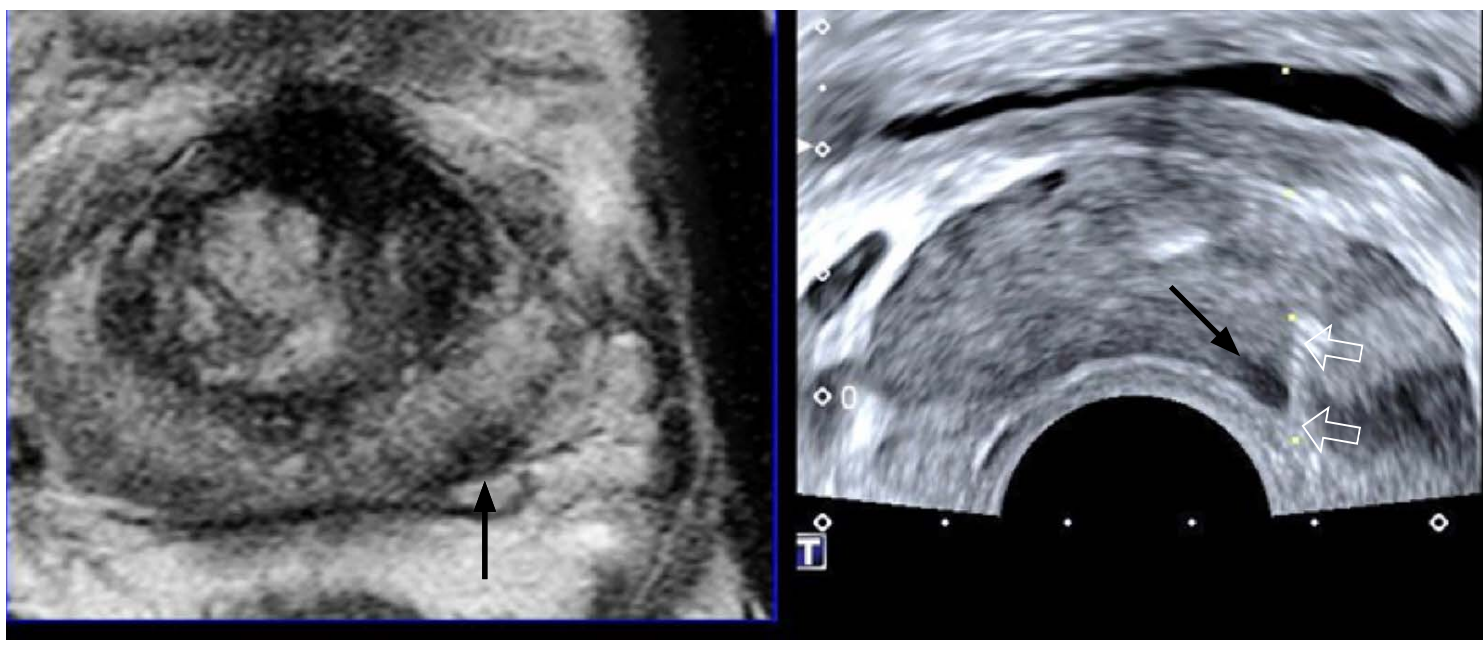

Fig. 10. A 67-year-old man with prostate cancer. Magnetic resonance imaging-transrectal ultrasound fusion imaging shows a left peripheral cancer (arrow), which was well targeted with an 18-gauge biopsy needle (open arrows). The prostate shape is deformed in the shape of a banana due to compression from the transrectal ultrasonography probe. The histologic diagnosis was Gleason score 7 adenocarcinoma sampled by a target biopsy.

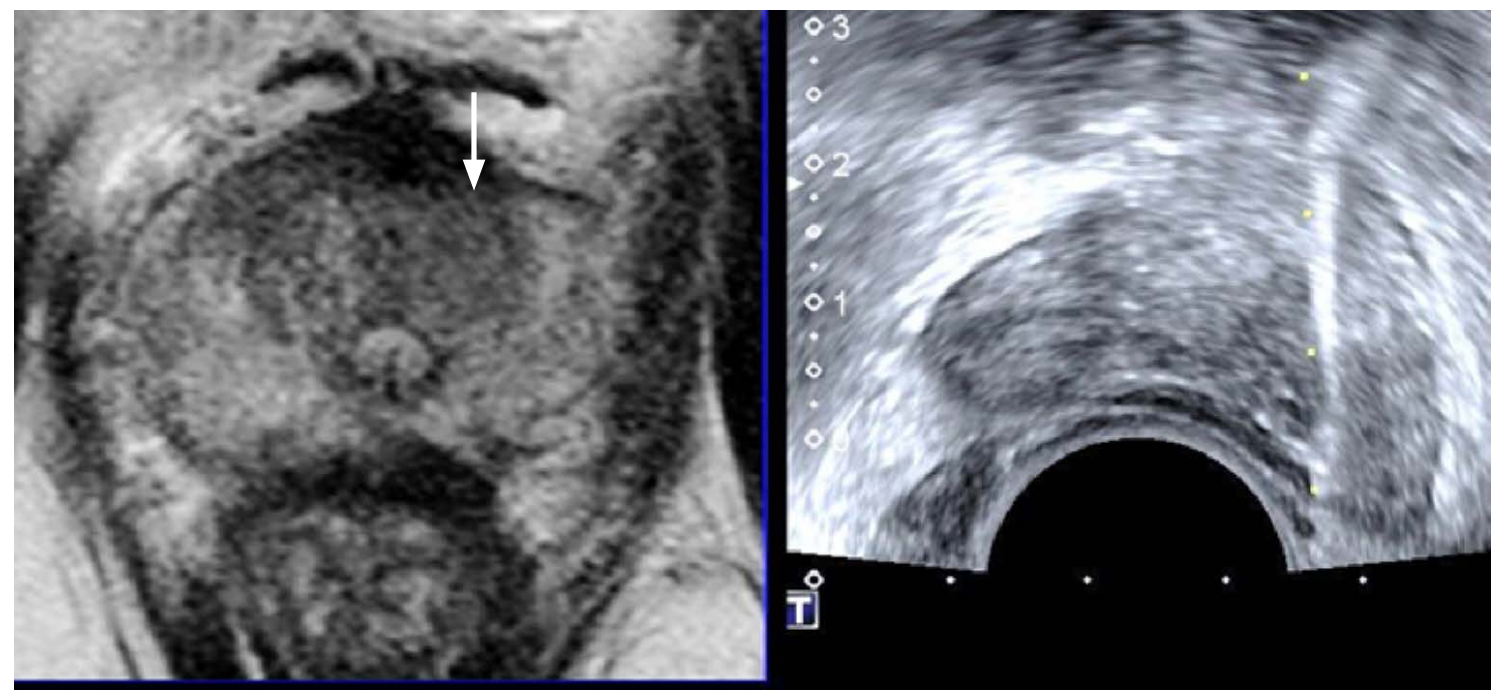

Fig. 11. A 69-year-old man with prostate cancer. Magnetic resonance imaging-transrectal ultrasound fusion imaging shows that a left transition lesion (arrow) is not clear on transrectal ultrasonography, but is visible on T2-weighted magnetic resonance imaging. This Gleason score 7 adenocarcinoma was not histologically sampled by a target biopsy, but by a systematic biopsy. 
4 or 5 lesions are frequently seen on TRUS images. Therefore, when a PI-RADS 4 or 5 lesion is detected on pre-biopsy MRI, TRUS alone should be performed first to determine whether the lesion is visible (Fig. 12). If it is visible using TRUS alone, a MRI-TRUS fusion biopsy is not necessary. Finally, a transperineal biopsy is recommended in patients with a history of the Miles operation due to rectal cancer [49]. When a PI-RADS 4 or 5 lesion is detected using MRI in such patients, a TRUS biopsy is not possible because they have no anus. Transperineal biopsy is one option for sampling the lesion (Fig. 13).

\section{US-Guided Thermal Ablation}

US-guided thermal ablation has been accepted as an alternative treatment for liver $[50,51]$ and thyroid tumours $[52,53]$, because

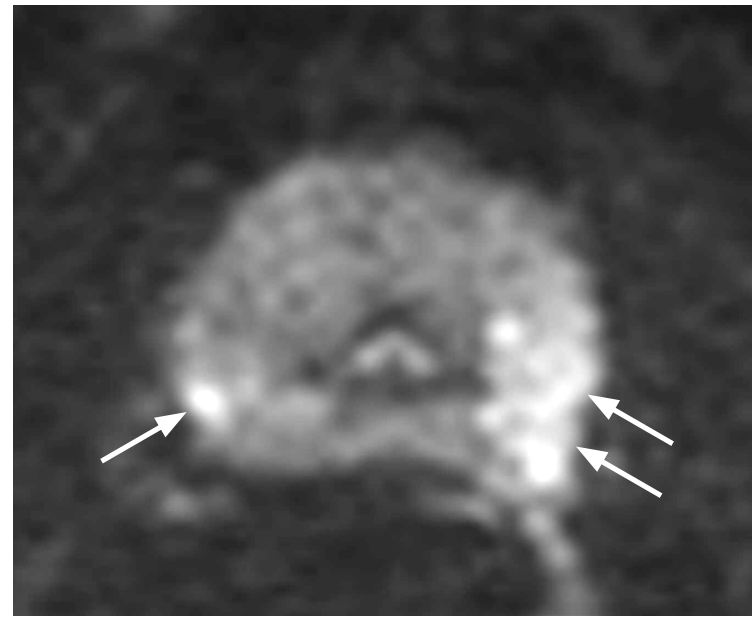

A

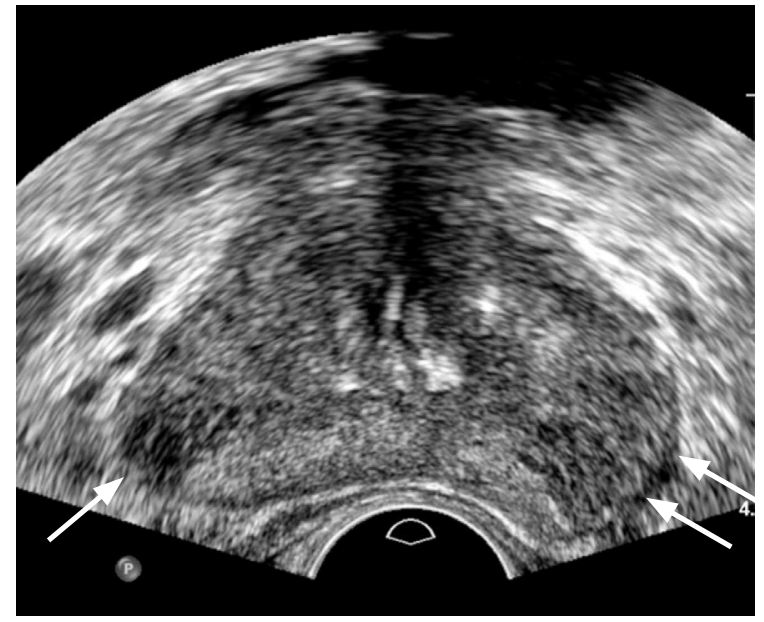

B

Fig. 12. A 65-year-old man with prostate cancer.

A. Diffusion-weighted axial magnetic resonance imaging shows a left Prostate Imaging and Report and Data System (PI-RADS) 5 cancer (arrows) and a right PI-RADS 4 cancer (arrow). These lesions are both hyperintense peripheral cancers with strong diffusion restriction. B. Transrectal ultrasonography shows that the right (arrow) and left (arrows) cancers are clearly visible. Both lesions were histologically confirmed as Gleason score 8 adenocarcinoma via a transrectal ultrasonography-guided biopsy.

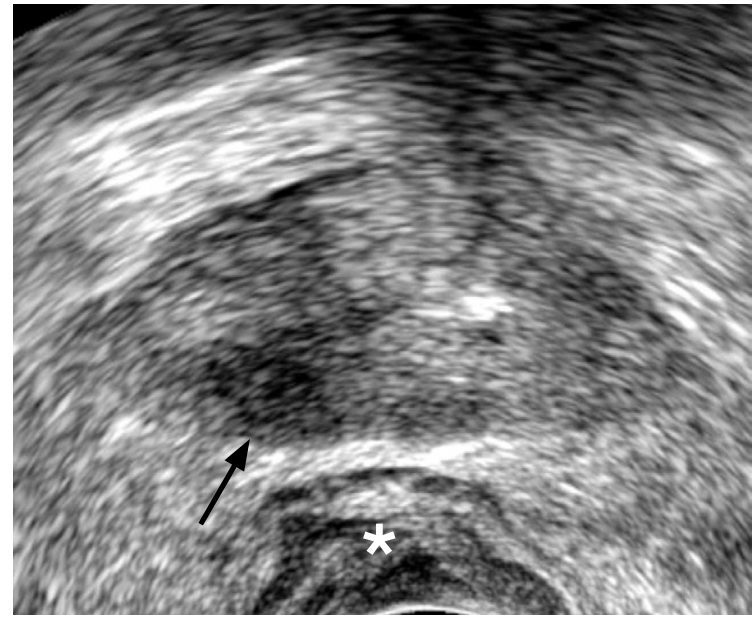

A

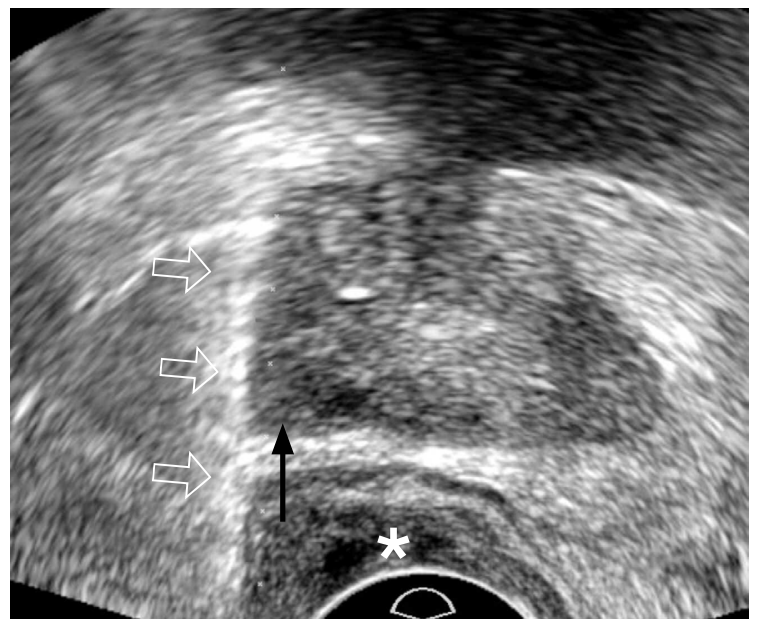

B

Fig. 13. A 71-year-old man with prostate cancer.

A. Transperineal ultrasonography shows a hypoechoic right peripheral lesion (arrow). The patient underwent a Miles operation due to rectal cancer 10 years ago. An asterisk indicates a perineal subcutaneous fat layer. B. Transperineal ultrasonography shows an 18-gauge biopsy needle (open arrows) traversing the lesion (arrow). An asterisk indicates a perineal subcutaneous fat layer. The histologic diagnosis was confirmed as Gleason score 8 adenocarcinoma. 
these organs provide a good sonic window. However, US cannot be used so readily to guide the treatment of renal and adrenal tumours using radiofrequency ablation (RFA) [54], cryoablation [55], or microwave ablation, although some investigators have reported that US guidance was useful when ablating renal masses [56-60]. Successful ablation requires complete treatment of the tumour margin as well as the tumour. Using US, it is difficult to depict the tumour margin during the ablation procedure (Fig. 14); the echogenic bubbles of the radiofrequency and microwave ablation procedures, as well as the echogenic ice balls that occur during cryoablation, are such strong reflectors of US that neither the posterior regions of a tumour nor the posterior tumour margin can be precisely assessed during ablation procedures. Park et al. [54] reported that the incidence of residual or recurrent renal cell carcinoma was higher when using US-guided RFA than when using CT-guided RFA. For these reasons, CT or MRI is preferred to guide thermal ablation in treating renal or adrenal tumours.

However, US guidance does not entail the radiation dose that occurs during CT-guided RFA or cryoablation $[61,62]$. When a lesion is being targeted, the radiation dose is highest during CT-guided

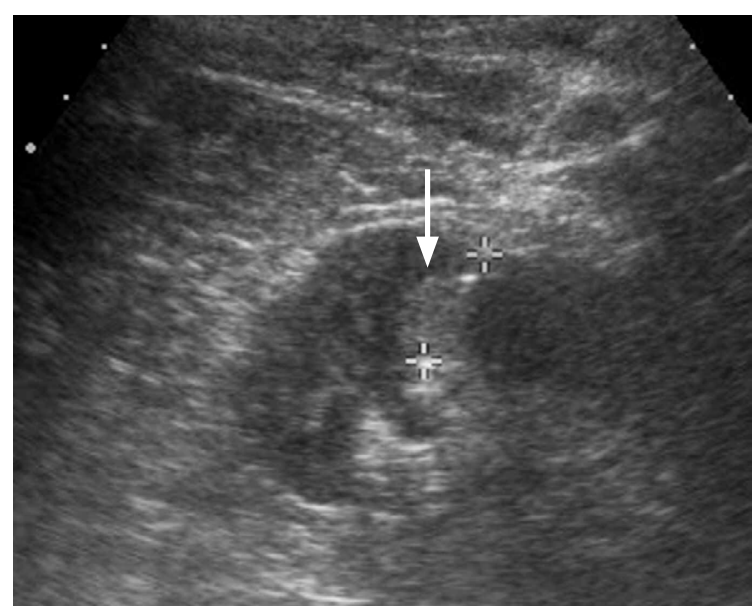

A

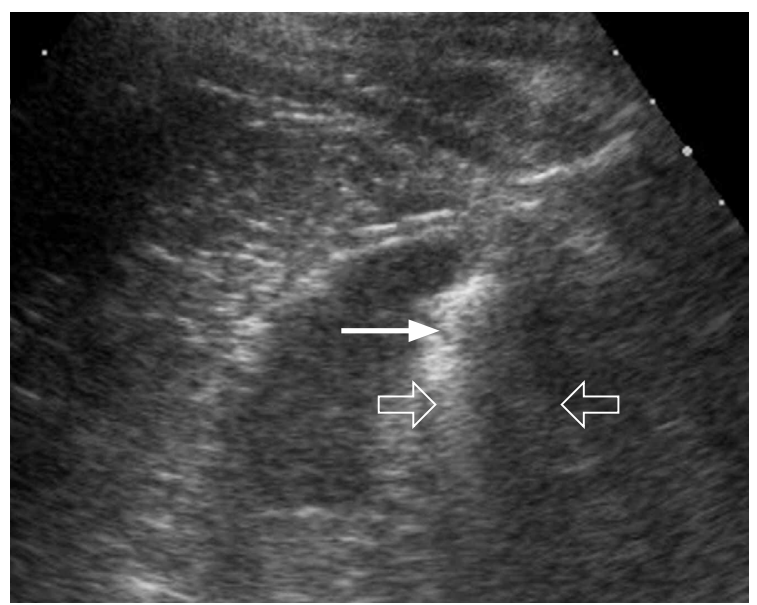

B

Fig. 14. A 44-year-old man with renal cell carcinoma.

A. Transabdominal ultrasonography shows a hyperechoic renal cell carcinoma (arrow) in the left kidney. The (+) markers indicate the length of the non-insulated electrode. B. Transabdominal ultrasonography shows hyperechoic air bubbles (arrow) covering the lesion. The sonic shadowing (open arrows) is so strong that the posterior tumour margin cannot be precisely identified.

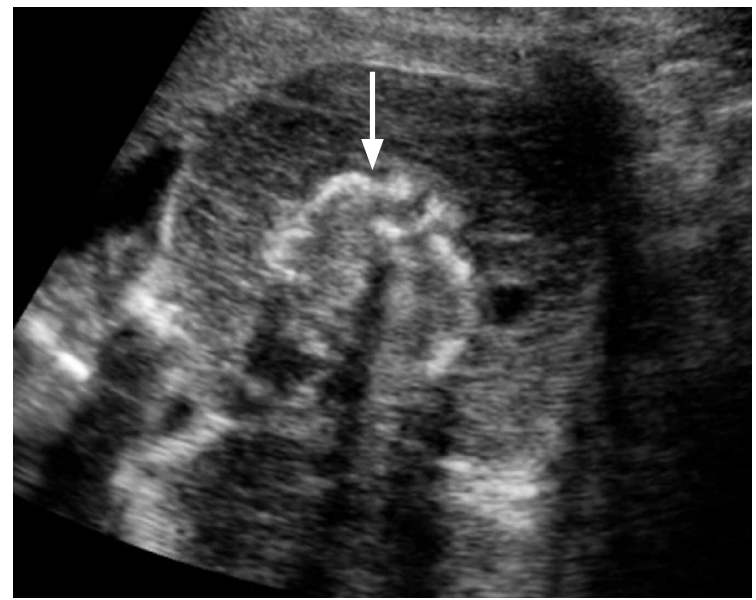

A

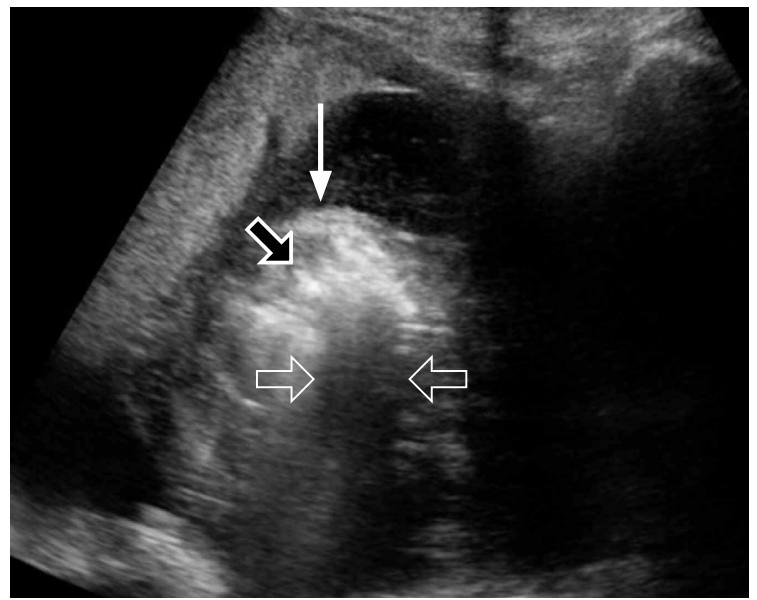

B

Fig. 15. An acardiac fetus in 20-week twins.

A. Transabdominal ultrasonography shows an acardiac fetus (arrow) who is small for the gestational age. B. Transabdominal ultrasonography shows that hyperechoic air bubbles (black open arrow) were created in the fetus (arrow) by radiofrequency ablation. White open arrows indicate sonic shadowing behind the air bubbles. 
ablation, because RFA electrodes or cryoablation applicators require multiple CT scans to achieve complete ablation [63]. Therefore, most scans take place during the targeting phase [63]. US guidance of RFA electrodes or cryoablation applicators would prevent the radiation dose associated with CT-guided RFA or cryoablation.

Interestingly, US is the modality of choice during the RFA treatment of an acardiac twin (Fig. 15) $[64,65]$. CT or MRI cannot be used in this clinical setting, because the fetus should not be exposed to such high levels of radiation, and because of foetal movement. In contrast to tumour ablation, the treatment goal of RFA is not complete ablation, but rather loss of viability. In fact, excessive ablation may induce the early delivery of the other normal fetus. Occasionally, the blood flow in the umbilical artery and vein must be checked using colour Doppler US. If blood flow is not seen in the umbilical vessels, ablation should be stopped to prevent unnecessary induction.

\section{Conclusion}

US guidance is useful for aspiration, biopsy, and ablation in the treatment of GU tract diseases. Radiologists should be familiar with the basic principles and various techniques of US-guided GU interventions. As such, radiologists can improve the diagnostic or therapeutic outcomes of US-guided procedures conducted in the GU organs.

ORCID: Byung Kwan Park: http://orcid.org/0000-0002-4114-8859

\section{Conflict of Interest}

No potential conflict of interest relevant to this article was reported.

\section{References}

1. Douglas BR, Charboneau JW, Reading CC. Ultrasound-guided intervention: expanding horizons. Radiol Clin North Am 2001;39:415-428.

2. Chin KJ, Perlas A, Chan VW, Brull R. Needle visualization in ultrasound-guided regional anesthesia: challenges and solutions. Reg Anesth Pain Med 2008;33:532-544.

3. Mohsen T, Gomha MA. Treatment of symptomatic simple renal cysts by percutaneous aspiration and ethanol sclerotherapy. BJU Int 2005:96:1369-1372.

4. Paananen I, Hellstrom P, Leinonen S, Merikanto J, Perala J, Paivansalo $\mathrm{M}$, et al. Treatment of renal cysts with single-session percutaneous drainage and ethanol sclerotherapy: long-term outcome. Urology 2001;57:30-33.

5. Ali TA, Abdelaal MA, Enite A, Badran YA. Ultrasound-guided percutaneous sclerotherapy of simple renal cysts with n-butyl cyanoacrylate and iodized oil mixture as an outpatient procedure. Urol Ann 2016:8:51-55.

6. Spigos D, Capek V. Ultrasonically guided percutaneous aspiration of lymphoceles following renal transplantation: a diagnostic and therapeutic method. J Clin Ultrasound 1976;4:45-46.

7. Silver TM, Campbell D, Wicks JD, Lorber MI, Surace P, Turcotte J. Peritransplant fluid collections: ultrasound evaluation and clinical significance. Radiology 1981;138:145-151.

8. Guariglia L, Conte M, Are P, Rosati P. Ultrasound-guided fine needle aspiration of ovarian cysts during pregnancy. Eur J Obstet Gynecol Reprod Biol 1999;82:5-9.

9. Khaw KT, Walker WJ. Ultrasound guided fine needle aspiration of ovarian cysts: diagnosis and treatment in pregnant and nonpregnant women. Clin Radiol 1990;41:105-108.

10. Anteby EY, Rahav G, Hanoch J, Shimonovitz S, Yagel S, Laufer N Ultrasound-guided transvaginal aspiration in the management of actinomyces pelvic abscess. Infect Dis Obstet Gynecol 1996;4:298300.

11. Corsi PJ, Johnson SC, Gonik B, Hendrix SL, McNeeley SG Jr, Diamond MP. Transvaginal ultrasound-guided aspiration of pelvic abscesses. Infect Dis Obstet Gynecol 1999;7:216-221.

12. Silverman SG, Gan YU, Mortele KJ, Tuncali K, Cibas ES. Renal masses in the adult patient: the role of percutaneous biopsy. Radiology 2006;240:6-22.

13. Silverman $S G$, Israel $G M$, Herts $B R$, Richie JP. Management of the incidental renal mass. Radiology 2008;249:16-31.

14. Sahni VA, Silverman SG. Imaging management of incidentally detected small renal masses. Semin Intervent Radiol 2014;31:9-19.

15. Park SY, Park BK, Kim CK, Kwon GY. Ultrasound-guided core biopsy of small renal masses: diagnostic rate and limitations. J Vasc Interv Radiol 2013;24:90-96.

16. Johnson PT, Nazarian LN, Feld RI, Needleman L, Lev-Toaff AS, Segal $S R$, et al. Sonographically guided renal mass biopsy: indications and efficacy. J Ultrasound Med 2001;20:749-753.

17. Caoili EM, Bude RO, Higgins EJ, Hoff DL, Nghiem HV. Evaluation of sonographically guided percutaneous core biopsy of renal masses. AJR Am J Roentgenol 2002;179:373-378.

18. Neuzillet $Y$, Lechevallier E, Andre M, Daniel L, Coulange C. Accuracy and clinical role of fine needle percutaneous biopsy with computerized tomography guidance of small (less than $4.0 \mathrm{~cm}$ ) renal masses. J Urol 2004;171:1802-1805.

19. Schmidbauer J, Remzi M, Memarsadeghi M, Haitel A, Klingler HC, Katzenbeisser D, et al. Diagnostic accuracy of computed tomography-guided percutaneous biopsy of renal masses. Eur Urol 2008;53:1003-1011.

20. Kim MH. CT-guided biopsy of entirely endophytic small renal masses: diagnostic rates and complications using standarddose and reduced-dose CT protocols. AJR Am J Roentgenol 
2017;208:1030-1036.

21. Barzon L, Sonino N, Fallo F, Palu G, Boscaro M. Prevalence and natural history of adrenal incidentalomas. Eur J Endocrinol 2003; 149:273-285.

22. Song JH, Chaudhry FS, Mayo-Smith WW. The incidental adrenal mass on CT: prevalence of adrenal disease in 1,049 consecutive adrenal masses in patients with no known malignancy. AJR Am J Roentgenol 2008;190:1163-1168.

23. Caoili EM, Korobkin M, Francis IR, Cohan RH, Dunnick NR. Delayed enhanced CT of lipid-poor adrenal adenomas. AJR Am J Roentgenol 2000;175:1411-1415.

24. Caoili EM, Korobkin M, Francis IR, Cohan RH, Platt JF, Dunnick NR, et al. Adrenal masses: characterization with combined unenhanced and delayed enhanced CT. Radiology 2002;222:629-633.

25. Park BK, Kim CK, Kim B, Lee JH. Comparison of delayed enhanced CT and chemical shift MR for evaluating hyperattenuating incidental adrenal masses. Radiology 2007;243:760-765.

26. Park JJ, Park BK, Kim CK. Adrenal imaging for adenoma characterization: imaging features, diagnostic accuracies and differential diagnoses. Br J Radiol 2016;89:20151018.

27. Paulsen SD, Nghiem HV, Korobkin M, Caoili EM, Higgins EJ. Changing role of imaging-guided percutaneous biopsy of adrenal masses: evaluation of 50 adrenal biopsies. AJR Am J Roentgenol 2004; 182:1033-1037.

28. Allen BC, Francis IR. Adrenal Imaging and Intervention. Radiol Clin North Am 2015;53:1021-1035.

29. Park SY, Park BK, Kim CK. Sonographically guided transhepatic core biopsies of right renal and adrenal masses: safety and short-term follow-up. J Ultrasound Med 2013;32:2013-2021.

30. Sharma KV, Venkatesan AM, Swerdlow D, DaSilva D, Beck A, Jain $\mathrm{N}$, et al. Image-guided adrenal and renal biopsy. Tech Vasc Interv Radiol 2010;13:100-109.

31. Bernardino ME, Walther MM, Phillips VM, Graham SD Jr, Sewell CW, Gedgaudas-McClees K, et al. CT-guided adrenal biopsy: accuracy, safety, and indications. AJR Am J Roentgenol 1985;144:67-69.

32. Tyng CJ, Bitencourt AG, Martins EB, Pinto PN, Chojniak R. Technical note: CT-guided paravertebral adrenal biopsy using hydrodissection: a safe and technically easy approach. Br J Radiol 2012;85:e339-e342.

33. Mody MK, Kazerooni EA, Korobkin M. Percutaneous CT-guided biopsy of adrenal masses: immediate and delayed complications. J Comput Assist Tomogr 1995; 19:434-439.

34. Wiseman DA, Hawkins R, Numerow LM, Taub KJ. Percutaneous renal biopsy utilizing real time, ultrasonic guidance and a semiautomated biopsy device. Kidney Int 1990;38:347-349.

35. Christensen J, Lindequist S, Knudsen DU, Pedersen RS. Ultrasoundguided renal biopsy with biopsy gun technique: efficacy and complications. Acta Radiol 1995;36:276-279.

36. Diaz-Buxo JA, Donadio JV Jr. Complications of percutaneous renal biopsy: an analysis of 1,000 consecutive biopsies. Clin Nephrol 1975;4:223-227.

37. O'Neill MJ, Rafferty EA, Lee SI, Arellano RS, Gervais DA, Hahn PF, et al. Transvaginal interventional procedures: aspiration, biopsy, and catheter drainage. Radiographics 2001;21:657-672.

38. Plett SK, Poder L, Brooks RA, Morgan TA. Transvaginal ultrasoundguided biopsy of deep pelvic masses: how we do it. J Ultrasound Med 2016;35:1113-1122.

39. Giede C, Toi A, Chapman W, Rosen B. The use of transrectal ultrasound to biopsy pelvic masses in women. Gynecol Oncol 2004;95:552-556.

40. Savader BL, Hamper UM, Sheth S, Ballard RL, Sanders RC. Pelvic masses: aspiration biopsy with transrectal US guidance. Radiology 1990;176:351-353.

41. Larsen T, Torp-Pedersen S, Bostofte E, Rank F. Transperineal fine needle biopsy of gynecological tumors guided by transrectal ultrasound: a new method. Gynecol Oncol 1985;22:281-287.

42. Hodge KK, McNeal JE, Stamey TA. Ultrasound guided transrectal core biopsies of the palpably abnormal prostate. J Urol 1989;142:66-70.

43. Shariat SF, Roehrborn CG. Using biopsy to detect prostate cancer. Rev Urol 2008; 10:262-280.

44. Daneshgari F, Taylor GD, Miller GJ, Crawford ED. Computer simulation of the probability of detecting low volume carcinoma of the prostate with six random systematic core biopsies. Urology 1995;45:604-609.

45. Pinto PA, Chung PH, Rastinehad AR, Baccala AA Jr, Kruecker J, Benjamin $\mathrm{CJ}$, et al. Magnetic resonance imaging/ultrasound fusion guided prostate biopsy improves cancer detection following transrectal ultrasound biopsy and correlates with multiparametric magnetic resonance imaging. J Urol 2011;186:1281-1285.

46. Fiard G, Hohn N, Descotes JL, Rambeaud JJ, Troccaz J, Long JA. Targeted MRI-guided prostate biopsies for the detection of prostate cancer: initial clinical experience with real-time 3-dimensional transrectal ultrasound guidance and magnetic resonance/transrectal ultrasound image fusion. Urology 2013;81:1372-1378.

47. Xu S, Kruecker J, Turkbey B, Glossop N, Singh AK, Choyke P, et al. Real-time MRI-TRUS fusion for guidance of targeted prostate biopsies. Comput Aided Surg 2008;13:255-264.

48. Barentsz JO, Weinreb JC, Verma S, Thoeny HC, Tempany CM, Shtern $F$, et al. Synopsis of the PI-RADS V2 guidelines for multiparametric prostate magnetic resonance imaging and recommendations for use. Eur Urol 2016;69:41-49.

49. Shinohara K, Gulati M, Koppie T, Terris MK. Transperineal prostate biopsy after abdominoperineal resection. J Urol 2003;169:141-144.

50. Livraghi T, Meloni F, Di Stasi M, Rolle E, Solbiati L, Tinelli C, et al. Sustained complete response and complications rates after radiofrequency ablation of very early hepatocellular carcinoma in cirrhosis: is resection still the treatment of choice? Hepatology 
2008;47:82-89.

51. Lencioni R, Cioni D, Crocetti L, Franchini C, Pina CD, Lera J, et al. Early-stage hepatocellular carcinoma in patients with cirrhosis: long-term results of percutaneous image-guided radiofrequency ablation. Radiology 2005;234:961-967.

52. Baek JH, Lee JH, Sung JY, Bae JI, Kim KT, Sim J, et al. Complications encountered in the treatment of benign thyroid nodules with USguided radiofrequency ablation: a multicenter study. Radiology 2012;262:335-342.

53. Wong $\mathrm{KP}$, Lang $\mathrm{BH}$. Use of radiofrequency ablation in benign thyroid nodules: a literature review and updates. Int I Endocrinol 2013;2013:428363.

54. Park BK, Kim CK, Choi HY, Lee HM, Jeon SS, Seo SI, et al. Limitation for performing ultrasound-guided radiofrequency ablation of small renal masses. Eur J Radiol 2010;75:248-252.

55. Allen BC, Remer EM. Percutaneous cryoablation of renal tumors: patient selection, technique, and postprocedural imaging. Radiographics 2010;30:887-900.

56. Veltri A, De Fazio G, Malfitana V, Isolato G, Fontana D, Tizzani A, et al. Percutaneous US-guided RF thermal ablation for malignant renal tumors: preliminary results in 13 patients. Eur Radiol 2004;14:2303-2310.

57. Veltri A, Garetto I, Pagano E, Tosetti I, Sacchetto P, Fava C. Percutaneous RF thermal ablation of renal tumors: is US guidance really less favorable than other imaging guidance techniques? Cardiovasc Intervent Radiol 2009;32:76-85.

58. Gao Y, Liang P, Yu X, Yu J, Cheng Z, Han Z, et al. Microwave treatment of renal cell carcinoma adjacent to renal sinus. Eur J Radiol 2016;85:2083-2089.

59. Yu J, Liang P, Yu XL, Cheng ZG, Han ZY, Mu MJ, et al. US-guided percutaneous microwave ablation of renal cell carcinoma: intermediate-term results. Radiology 2012;263:900-908.

60. Bassignani M, Moore Y, Watson L, Theodorescu D. Pilot experience with real-time ultrasound guided percutaneous renal mass cryoablation. J Urol 2004;171:1620-1623.

61. Atwell TD, Farrell MA, Callstrom MR, Charboneau JW, Leibovich $B C$, Patterson DE, et al. Percutaneous cryoablation of 40 solid renal tumors with US guidance and CT monitoring: initial experience. Radiology 2007;243:276-283.

62. Hinshaw JL, Shadid AM, Nakada SY, Hedican SP, Winter TC 3rd, Lee FT Jr. Comparison of percutaneous and laparoscopic cryoablation for the treatment of solid renal masses. AJR Am J Roentgenol 2008; 191:1159-1168.

63. Park BK, Morrison PR, Tatli S, Govindarajulu U, Tuncali K, Judy P, et al. Estimated effective dose of CT-guided percutaneous cryoablation of liver tumors. Eur J Radiol 2012;81:1702-1706.

64. Hirose M, Murata A, Kita N, Aotani H, Takebayashi K, Noda Y. Successful intrauterine treatment with radiofrequency ablation in a case of acardiac twin pregnancy complicated with a hydropic pump twin. Ultrasound Obstet Gynecol 2004;23:509-512.

65. Cabassa P, Fichera A, Prefumo F, Taddei F, Gandolfi S, Maroldi R, et al. The use of radiofrequency in the treatment of twin reversed arterial perfusion sequence: a case series and review of the literature. Eur J Obstet Gynecol Reprod Biol 2013;166:127-132. 